\title{
Effects of a Serotonin 2C Agonist and a 2A Antagonist on Actigraphy-Based Sleep Parameters Disrupted by Methamphetamine Self-Administration in Rhesus Monkeys
}

\author{
Maylen Perez Diaz', Monica L Andersen ${ }^{1,2}$, Kenner C Rice ${ }^{3}$ and Leonard L Howell ${ }^{*, 1,4}$ \\ 'Yerkes National Primate Research Center, Emory University, Atlanta, GA, USA; ${ }^{2}$ Departamento de Psicobiologia, Universidade Federal de São \\ Paulo (UNIFESP), São Paulo, SP, Brazil; ${ }^{3}$ Drug Design and Synthesis Section, Chemical Biology Research Branch, National Institutes of Drug Abuse, \\ Rockville, MD, USA; ${ }^{4}$ Department of Psychiatry and Behavioral Sciences, Emory University, Atlanta, GA, USA
}

\begin{abstract}
Sleep disorders and substance abuse are highly comorbid and we have previously shown that methamphetamine self-administration significantly disrupts activity-based sleep parameters in rhesus monkeys. To the best of our knowledge, no study has evaluated the effectiveness of any pharmacological intervention to attenuate the effects of methamphetamine on nighttime activity under well-controlled conditions in laboratory animals. Thus, we examined the effects of a 5- $\mathrm{HT}_{2 \mathrm{C}}$ receptor agonist, WAYI63909, and a 5- $\mathrm{HT}_{2 \mathrm{~A}}$ receptor antagonist, MI00907, given alone and in combination, on actigraphy-based sleep parameters disrupted by methamphetamine selfadministration in non-human primates. Adult male/female rhesus monkeys self-administered methamphetamine (0.03 mg/kg/injection, i.v.) under a fixed-ratio 20 schedule of reinforcement (60-min sessions once a day, 5 days per week). Nighttime activity was evaluated using Actiwatch monitors. WAYI 63909 (0.1, 0.3, and $1.0 \mathrm{mg} / \mathrm{kg})$, MI00907 (0.03, 0.1, and $0.3 \mathrm{mg} / \mathrm{kg})$, and a combination (0.1 mg/kg MI00 $+0.3 \mathrm{mg} / \mathrm{kg}$ WAY) were administered i.m. before lights-out. Each dose was given for five consecutive days during which self-administration took place in the morning. Both drugs improved activity-based sleep measures disrupted by methamphetamine by decreasing sleep latency and increasing sleep efficiency compared with vehicle. By combining these drugs, their individual effects were significantly enhanced. Agonists at the 5- $\mathrm{HT}_{2} \mathrm{C}$ receptor and antagonists at the 5- $\mathrm{HT}_{2 \mathrm{~A}}$ receptor show promise as potential treatments for the sleep-disrupting effects of stimulants when used alone and in combination. Combining subthreshold doses of WAY and MI00 produced significant improvements in nighttime activity measures while avoiding the general motor-decreasing effects of the high dose of WAY.

Neuropsychopharmacology (2017) 42, I53I-1538; doi: I0.1038/npp.2016.280; published online I8 January 2017
\end{abstract}

\section{INTRODUCTION}

Methamphetamine (METH) use is a growing public health issue (Marshall et al, 2012). For over a decade, METH has been one of the most widely abused illicit substances (Cruickshank and Dyer, 2009). In 2013, 38 million people worldwide used METH, totaling $0.7 \%$ of the global population (http://www.unodc.org/documents/data-and-analysis/

WDR2012/WDR_2012_web_small.pdf). Its use is correlated with several adverse mental, behavioral, and physical health outcomes. Of these, disturbed sleep is one of the most common and pronounced (Perez et al, 2008), and may be a risk factor for relapse to drug use (Hasler et al, 2012). Unfortunately, METH research has been limited and very few studies address the consequences of METH abuse on sleep.

There is a significant comorbidity between substance abuse involving stimulants and sleep disorders. Sleep is essential for

*Correspondence: Dr LL Howell, Yerkes National Primate Research Center, Emory University, 954 Gatewood Road N.E., Atlanta, GA 30329, USA, Tel: 404727 7786, Fax: 404727 I266,

E-mail: Ihowell@emory.edu

Received 25 June 2016; revised 28 November 2016; accepted 9 December 2016; accepted article preview 16 December 2016 psychological and physical wellbeing (Tufik et al, 2009) and disrupted sleep has been associated with reduced cognitive function (Qureshi et al, 2014), increased risk of depression (Zhai et al, 2015) and risk of suicide in depressed patients (Bryan et al, 2015), dysregulation of the hypothalamicpituitary-adrenal axis (Castro-Diehl et al, 2015), and increased risk of developing metabolic syndrome (Troxel et al, 2010), obesity (Buxton and Marcelli, 2010), and heart disease (Grandner et al, 2012; Appelhans et al, 2013).

Studying the effects of METH on sleep in humans presents many issues that can be eliminated in laboratory animal models. Studies in nonhuman primates (NHPs) have employed the drug self-administration (SA) paradigm, which has well-documented validity as a model of drug use in humans (Johanson and Schuster, 1981; Gardner, 2000). METH dose-dependently functions as a reinforcer in rhesus macaques (Freeman et al, 2010) under different schedules of reinforcement, sustained over multiple experimental sessions. Moreover, non-invasive telemetric monitoring has shown that amphetamine (Murnane et al, 2013a) and METH (Andersen et al, 2013) impair activity-based parameters of sleep in NHPs. In vivo microdialysis studies suggest that these effects are mediated by the effectiveness of 
psychostimulants to increase extracellular dopamine (DA) in the nucleus accumbens and the caudate nucleus (Andersen et al, 2010; Murnane et al, 2013a).

Few studies have evaluated potential pharmacological treatments to improve sleep disrupted by stimulant use. Serotonin signaling modulates the DA system, making it a prime candidate poised to impact the DA-driven arousal effects of psychostimulants. However, there are many serotonin receptor (5-HTR) subtypes with varied and sometimes opposing functions, so high selectivity for one subtype is key in determining the specificity of behavioral effects. Specifically, the serotonin $5-\mathrm{HT}_{2 \mathrm{~A}} \mathrm{R}$ and $5-\mathrm{HT}_{2 \mathrm{C}} \mathrm{R}$ subtypes play important roles in sleep-wake behavior. For example, $5-\mathrm{HT}_{2 \mathrm{~A}} \mathrm{R}$ and $5-\mathrm{HT}_{2 \mathrm{C}} \mathrm{R}$ knock-out mice show a significant increase of wakefulness, abnormal rapid eye movement sleep, and a reduction of slow wave sleep, which have been attributed to the increase of catecholaminergic neurotransmission involving mainly the dopaminergic system (Adrien, 2004; Frank, Stryker and Tecott, 2002). Further, systemic administration of the $5-\mathrm{HT}_{2 \mathrm{~A} / 2 \mathrm{C}} \mathrm{R}$ antagonist ritanserin and the selective $5-\mathrm{HT}_{2 \mathrm{~A}} \mathrm{R}$ antagonists volinanserin and pruvanserin has been shown to induce a significant increase of slow wave sleep in rodents and patients with chronic primary insomnia (Monti, 2011). Interestingly, selective antagonism of the $5-\mathrm{HT}_{2 \mathrm{~A}} \mathrm{R}$ attenuates the acute effects of non-contingent amphetamine on arousal, as well as DA overflow in the caudate nucleus in NHPs (Murnane et al, 2013b). However, no study has evaluated the efficacy of $5-\mathrm{HT}_{2 \mathrm{~A}}$ antagonists in the context of sleep that has been disrupted chronically by METH SA. Selective $5-\mathrm{HT}_{2 \mathrm{C}} \mathrm{R}$ agonists attenuate cocaine-induced DA overflow in NHPs (Manvich et al, 2012). Yet, it remains unclear whether $5-\mathrm{HT}_{2 \mathrm{C}}$ agonists can decrease the sleep-disrupting effects of METH SA.

The present study assessed the effectiveness of a highly selective $5-\mathrm{HT}_{2 \mathrm{C}}$ agonist and a $5-\mathrm{HT}_{2 \mathrm{~A}}$ antagonist to attenuate the effects of METH SA on nighttime activity in rhesus monkeys using Actiwatch monitors. Cunningham et al (2013) demonstrated that sub-threshold doses of $5-\mathrm{HT}_{2 \mathrm{C}}$ agonists and $5-\mathrm{HT}_{2 \mathrm{~A}}$ antagonists, each ineffective when given alone, significantly suppressed cocaine-induced hyperactivity, impulsive action evoked by cocaine, as well as cue- and cocaine-primed reinstatement of cocaine-seeking behavior in rodents. Thus, we hypothesized that these drugs would each independently improve actigraphy-based sleep measures disrupted by METH SA, and that coadministration of these drugs would enhance their separate effects. Studies focusing on potential pharmacological manipulations for improving sleep disrupted by METH use will provide a broader understanding of the underlying neural mechanisms and neurotransmitter systems contributing to these sleep-disrupting effects, as well as help identify potential treatment interventions.

\section{MATERIALS AND METHODS}

Experiment 1 evaluated the effects of a $5-\mathrm{HT}_{2 \mathrm{C}}$ agonist and a $5-\mathrm{HT}_{2 \mathrm{~A}}$ antagonist on actigraphy-based sleep measures during METH SA. Experiment 2 evaluated the effects of these drugs on baseline sleep. Experiment 3 evaluated the effects of these drugs on baseline daytime activity. For experiments 2 and 3, all measures were taken in the absence of METH SA.

\section{Subjects}

Adult rhesus monkeys (Macaca mulatta), four males (ROf8, RLk4, RJ18 and Kn9) and seven females (RVm8, Zs9, Na4, Rh7, Th8, Ka10 and Kf9), weighing 9-16 kg served as subjects for these studies. They were individually housed in stainless steel home cages and fed Purina monkey chow (Ralston Purina, St Louis, MO, USA), supplemented with fruit and vegetables. Water was continuously available in the colony, which was maintained at an ambient temperature of $22 \pm 2{ }^{\circ} \mathrm{C}$ at $45-50 \%$ humidity and a $12 \mathrm{~h}$ light/dark cycle (lights on at hour 0700; lights off at hour 1900). Environmental enrichment was provided on a regular rotating basis. All procedures strictly followed the National Institutes of Health Guide for the Care and Use of Laboratory Animals (Eighth Edition, revised 2010), and were approved by the Institutional Animal Care and Use Committee of Emory University. Subjects were fitted with collars (Primate Products) and had a previous history of METH SA. However, none had any exposure to experimental drugs for a minimum of 6 months prior to these studies.

\section{Drugs}

Methamphetamine ( \pm racemic) $\mathrm{HCl}$ was provided by the National Institute on Drug Abuse (Research Technology Branch, Research Triangle Park, NC, USA), and was dissolved in sterile physiological saline. WAY163909 (WAY) $\mathrm{HCl}$ ((7b-R,10a-R)-1,2,3,4,8,9,10,10a-octahydro-7bH-cyclopenta[b] $[1,4]$ diazepino $\left[6,7,1\right.$ hi] indole), the $5-\mathrm{HT}_{2 \mathrm{C}}$ agonist, was a generous gift from Pfizer Inc. (New York, NY) and was dissolved in $10 \mathrm{mg} / \mathrm{ml} \beta$-cyclodextrin. WAY was identified as a $5-\mathrm{HT}_{2 \mathrm{C}} \mathrm{R}$ agonist as it exhibits high affinity $\left(K_{\mathrm{i}}=10.5 \mathrm{nM}\right)$ and full efficacy $(90 \%$ relative to $5-\mathrm{HT})$ at the $5-\mathrm{HT}_{2 \mathrm{C}} \mathrm{R}$ and a low affinity $\left(K_{\mathrm{i}}=212 \mathrm{nM}\right)$ at the $5-\mathrm{HT}_{2 \mathrm{~A}} \mathrm{R}$ (Dunlop et al, 2005). M100907 (M100) HCl (R-(1)-(2,3-dimethoxyphenyl)-1(2-(4-fluorophenylethyl))-4-piperidine-methanol), the $5-\mathrm{HT}_{2 \mathrm{~A}}$ antagonist, was synthesized at the Chemical Biology Research Branch, National Institute on Drug Abuse and National Institute on Alcohol Abuse and Alcoholism at the National Institutes of Health (Bethesda, MD, USA) and was dissolved in $0.9 \% \mathrm{NaCl}$. M100 was identified as a $5-\mathrm{HT}_{2 \mathrm{~A}} \mathrm{R}$ antagonist as it has been shown to bind to $5-\mathrm{HT}_{2 \mathrm{~A}} \mathrm{R}$ with high affinity $\left(K_{\mathrm{i}}=1.9 \mathrm{nM}\right)$ and is approximately 16 times more selective for the $5-\mathrm{HT}_{2 \mathrm{~A}} \mathrm{R}$ over the $5-\mathrm{HT}_{2 \mathrm{C}} \mathrm{R}$ (Bromidge et al, 2000; Knight et al, 2004).

\section{Actigraphy-Based Measures of Sleep and Daytime Activity}

Actigraphy is one of the most commonly used (Terrill et al, 2010) and highly translational methods of assessing different measures of sleep, as it is widely used in human studies (Smagula et al 2016; Baron et al 2016). Actiwatch monitors (Mini Mitter, Bend, OR, USA), a reliable non-invasive method for activity monitoring (Andersen et al, 2010, 2012), were attached to our subjects' collars. For experiments 1-2 we assessed the following parameters: sleep efficiency (\% of dark phase spent sleeping), sleep latency (number of minutes 
from lights-out to first sleep bout) and fragmentation (immobile bouts during the dark phase that lasted less than 1 min during the sleep recording period). Fragmentation index is a measure of how much a rest period is disjoined by physical movements and is indicative of restlessness, taking into account the amount of wake episodes during the sleep period. Sleep bouts are the number of sleep episode events that take place during the entire period of recording. For experiment 3, total daytime activity measures were assessed with Actiwatch monitors. All parameters were calculated using the Actiware Sleep 3.4 software program, which established a threshold of very low activity periods identified as 'sleep'. These actigraphy-based measures of sleep have been extensively validated in humans (Terrill et al, 2010; Mann et al, 2005) using direct measures, such as polysomnography.

\section{Experiment 1}

Methamphetamine SA. Subjects were surgically prepared with chronic indwelling venous catheters. The apparatus and SA procedure are described in detail by Howell and Wilcox (2001). Subjects self-administered METH (0.03 mg/kg/injection) i.v. during 60-min sessions, once a day, 5 days per week, starting between hours 0800 and 1000 . The dose of METH was chosen because it significantly and consistently disrupts activity-based sleep parameters in rhesus monkeys (Andersen et al, 2013). Subjects were seated in primate chairs (Primate Products) and placed in soundattenuating experimental chambers for the duration of the session, then returned and maintained in their home cages. During test sessions, the chambers were illuminated with a red light (discriminative stimulus). Completion of the FR20 response requirement resulted in a change in the stimulus light from red to white for $15 \mathrm{~s}$ and a METH infusion $(0.03 \mathrm{mg} / \mathrm{kg}$ in $0.5 \mathrm{ml}$ infused over $3 \mathrm{~s})$, followed by a $60 \mathrm{~s}$ time out, during which all lights were turned off and responding had no programmed consequences. Following the timeout, the red light was presented again to signal the opportunity to earn another infusion. Subjects could selfadminister up to 60 infusions per session, such that the maximum total drug intake would not exceed $1.8 \mathrm{mg} /$ kg METH.

Nighttime drug pre-treatments. Subjects (Of8, Vm8, Lk4 and J18) underwent 10 weeks of METH SA. Each week, subjects received one of 10 nighttime pre-treatments for five consecutive nights (Mon-Fri) following METH SA in the mornings: (1) no pre-treatment, (2) M100 vehicle pretreatment, (3-5) $0.03,0.1$, and $0.3 \mathrm{mg} / \mathrm{kg} \mathrm{M} 100$ pretreatments, (6) WAY vehicle pre-treatment, (7-9) $0.1,0.3$ and $1.0 \mathrm{mg} / \mathrm{kg}$ WAY pre-treatments, and (10) $0.1 \mathrm{mg} / \mathrm{kg}$ $\mathrm{M} 100+0.3 \mathrm{mg} / \mathrm{kg}$ WAY combination pre-treatment. Sat-Sun were days off, with no METH SA or pre-treatments. The highest ineffective dose of both WAY $(0.3 \mathrm{mg} / \mathrm{kg})$ and M100 $(0.1 \mathrm{mg} / \mathrm{kg})$ was chosen for drug combination experiments. Before METH SA began, baseline nighttime activity patterns were measured for 1 week (Mon-Fri) using Actiwatch monitors. Afterward, subjects began the METH SA protocol. For all experimental manipulations, except the 'no pretreatment' condition, subjects received an i.m. injection every SA day before lights-out (at 1815 for WAY and at 1800 for
M100). Doses of M100 were chosen based on cocaineinduced reinstatement studies in NHPs (Murnane et al, 2013a) and doses of WAY were chosen based on METH SA in NHPs (unpublished data).

\section{Experiment 2}

Nighttime WAY163909 pre-treatments. Subjects (Of8, Vm8, Lk4, Zs9 and J18) were studied under two experimental conditions: (1) vehicle and (2) the highest dose of WAY $(1.0 \mathrm{mg} / \mathrm{kg})$ pre-treatment. Each treatment was given i.m. for five consecutive days $45 \mathrm{~min}$ before lights out (at 1815). There was a 2-day period separating each experimental condition. Nighttime activity measures were collected for the five consecutive days and averaged for each treatment condition.

Nighttime M100907 pre-treatments. Subjects (Kn9, Na4, Rh7, Th8 and Ka10) were studied under two experimental conditions: (1) vehicle and (2) the highest dose of M100 $(0.3 \mathrm{mg} / \mathrm{kg})$ pre-treatment. These treatments were administered similarly to the WAY treatments described in the section above, except they were given $1 \mathrm{~h}$ before lights out (at 1800 ).

\section{Experiment 3}

Daytime WAY163909 pre-treatments. Subjects (Of8, Vm8, Lk4, Zs9 and J18) were studied under four experimental conditions: (1) WAY vehicle pre-treatment, (2) $0.1 \mathrm{mg} / \mathrm{kg}$ WAY pre-treatment, (3) $0.3 \mathrm{mg} / \mathrm{kg}$ WAY pretreatment and (4) $1.0 \mathrm{mg} / \mathrm{kg}$ WAY pre-treatment. Treatments were separated by 1-2 days. Each treatment was given as an i.m. injection immediately after lights on (at 07:30). Total daytime activity measures were collected for each treatment condition.

Daytime M100907 pre-treatments. Subjects (Vm8, Lk4, Zs9 and Kf9) were studied under four experimental conditions: (1) M100 vehicle pre-treatment, (2) $0.03 \mathrm{mg} / \mathrm{kg}$ M100 pre-treatment, (3) $0.1 \mathrm{mg} / \mathrm{kg}$ M100 pre-treatment and (4) $0.3 \mathrm{mg} / \mathrm{kg}$ M100 pre-treatment. These treatments were administered similarly to the WAY treatments described in the section above.

\section{Statistical Analysis}

For all experiments, treatment conditions were randomized and counterbalanced across subjects. For Experiment 1, the effects of METH SA and all nighttime pre-treatments on actigraphy-based sleep measures were averaged over five consecutive days for each subject and analyzed using one-way repeated measures analysis of variance ANOVA. Post hoc analyses were conducted with Dunnett's test. For Experiment 2, paired $t$-tests were used to determine the effects of pre-treatments on baseline nighttime activity. Similarly, measures taken under all pre-treatment conditions were averaged over five consecutive days for each subject. For Experiment 3, the effects of treatments on baseline daytime activity were measured only once per subject and analyzed using RM ANOVA and Dunnett's post hoc. Statistical analyses were carried out using GraphPad Prism 6 (GraphPad Software, San Diego, CA, USA) and significance was accepted at an $\alpha$ of 0.05 . 
a

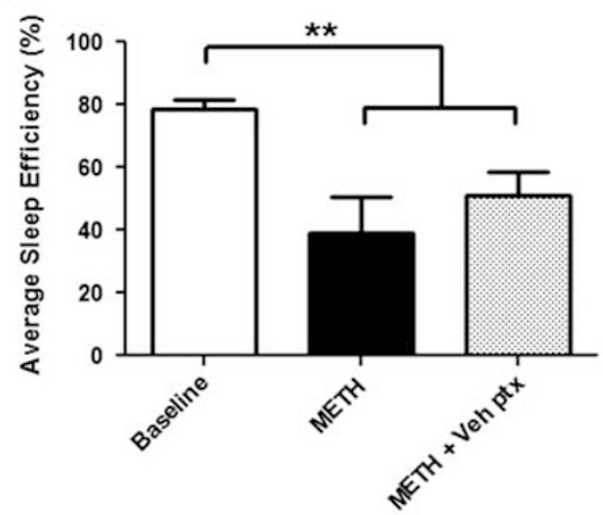

d

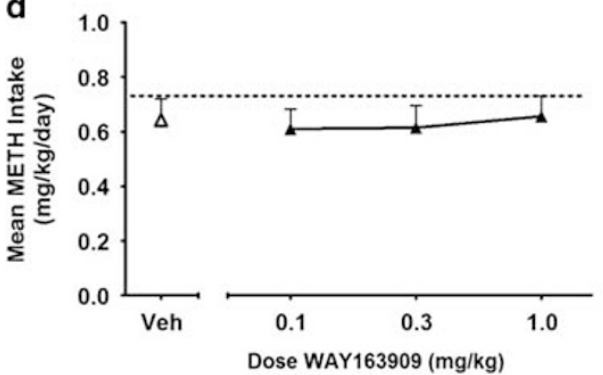

b

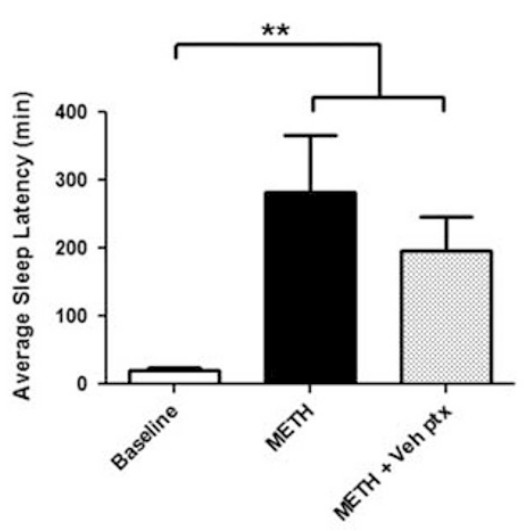

e

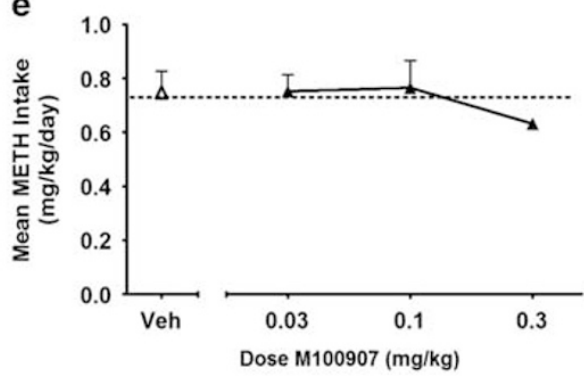

C

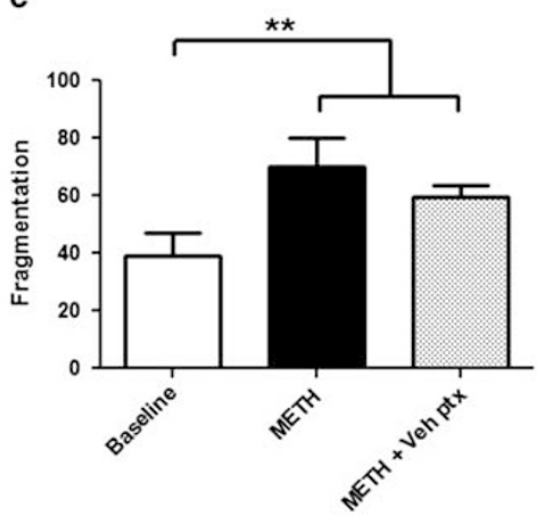

f

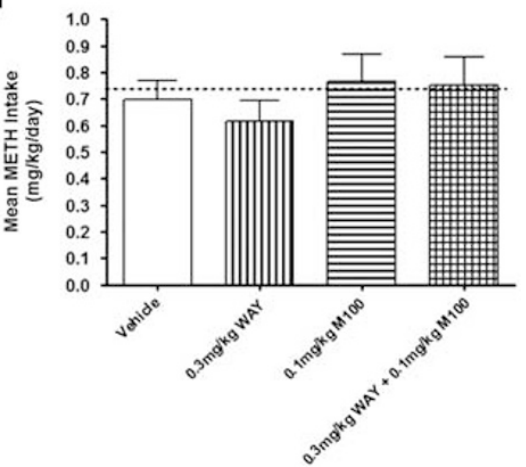

Figure I METH SA effects on actigraphy-based sleep parameters and nighttime pre-treatment effects on METH SA. Subjects ( $N=4)$ self-administered METH (0.03 mg/kg/injection) for 10 weeks. Each week, subjects received nighttime pre-treatments, administered for five consecutive nights following METH SA in the morning. During METH SA, activity-based parameters of sleep efficiency $(F(2,3)=17.73, p=0.0030)$, sleep latency $(F(2,3)=1 \mid .25, p=0.0093)$, and fragmentation $(F(2,3)=14.77, p=0.0048)$ were significantly disrupted compared with baseline (no METH SA). Under the METH SA+vehicle nighttime pretreatment condition, these parameters did not significantly differ from those during METH SA with no treatment and were still disrupted compared with baseline. (a) Sleep efficiency (\%), (b) sleep latency (minutes), and (c) fragmentation (unitless index). Nighttime pre-treatments with WAY ( $F(3,3)=2.01$, $p=0.1363)$, MIOO $(F(3,3)=1.82, p=0.1695)$, and a combination of both $(F(3,3)=1.24, p=0.3500)$ had no effect on METH intake during SA compared with vehicle. (d) WAY, (e) MIO0 and (f) combination. Dotted lines indicate baseline levels of METH intake in the absence of any nighttime pre-treatment. Means \pm SE shown. METH SA, methamphetamine self-administration. ${ }^{*} p<0.05, * * 0<0.01$.

\section{RESULTS}

\section{Experiment 1}

METH SA effects on actigraphy-based sleep parameters. Subjects $(N=4)$ self-administered METH $(0.03 \mathrm{mg} / \mathrm{kg} / \mathrm{injec}$ tion) for the 10 weeks of experimental manipulations. Sleep efficiency $(\mathrm{F}(2,3)=17.73, p=0.0030)$, latency $(\mathrm{F}(2,3)=11.25$, $p=0.0093)$, and fragmentation $(\mathrm{F}(2,3)=14.77, p=0.0048)$ were all significantly affected by METH SA compared with baseline. Sleep efficiency dropped from $80 \%$ at baseline to $40 \%$ during SA (Figure 1a). Similarly, sleep latency increased from $20 \mathrm{~min}$ at baseline to over $4 \mathrm{~h}$ during SA (Figure $\mathrm{lb}$ ) and fragmentation almost doubled during METH SA compared with baseline (Figure 1c). Average METH intake (Figure $1 \mathrm{~d}-\mathrm{f}$ ) was not significantly affected by any of the nighttime pre-treatments $(p>0.05)$.

5- $\mathrm{HT}_{2 \mathrm{C}} \mathrm{R}$ agonist, 5- $\mathrm{HT}_{2 A} \mathrm{R}$ antagonist and METH SA on actigraphy-based sleep measures. Nighttime pretreatments of WAY were tested $(N=4)$ to determine if it could attenuate the effects of METH SA on actigraphy-based measures of sleep. The highest dose of WAY $(1.0 \mathrm{mg} / \mathrm{kg})$ significantly increased sleep efficiency (Figure 2a) by $15 \%$
$(\mathrm{F}(3,3)=4.90, \quad p=0.0142)$ and decreased sleep latency (Figure $2 \mathrm{~b}$ ) by $1.5 \mathrm{~h}(\mathrm{~F}(3,3)=6.04, p=0.0067)$ compared with vehicle. For sleep fragmentation (Figure $3 \mathrm{c}$ ), there was a significant main effect of drug treatment $(\mathrm{F}(3,3)=3.90$, $p=0.0297$ ); however, post hoc analysis did not reveal a significant difference between any WAY dose and vehicle $(p>0.05)$. Similar pre-treatments using M100 were also tested $(N=4)$. The highest dose of M100 $(0.3 \mathrm{mg} / \mathrm{kg})$ significantly increased sleep efficiency (Figure $2 \mathrm{~d}$ ) by $18 \%$ $(\mathrm{F}(3,3)=9.24, \quad p=0.0041)$, decreased sleep latency (Figure $2 \mathrm{e}$ ) by $1.5 \mathrm{~h}(\mathrm{~F}(3,3)=7.288, p=0.0088)$ and decreased fragmentation (Figure 2f) by $15 \%(F(3,3)=7.22$, $p=0.0091)$ compared with vehicle.

Co-administration of a 5-HT $T_{2 C} R$ agonist and $5-H T_{2 A} R$ antagonist on METH-induced disruption of actigraphybased sleep measures. To demonstrate that agonism at the $5-\mathrm{HT}_{2 \mathrm{C}} \mathrm{R}$ and antagonism at the $5-\mathrm{HT}_{2 \mathrm{~A}} \mathrm{R}$ can be combined to enhance the individual effects of each, we chose the highest ineffective dose of WAY $(0.3 \mathrm{mg} / \mathrm{kg})$ and M100 $(0.1 \mathrm{mg} / \mathrm{kg})$ at attenuating the effects of METH SA on nighttime activity when administered alone and administered them in combination $(N=4)$. The combination dose $(0.3 \mathrm{mg} / \mathrm{kg}$ WAY 
a
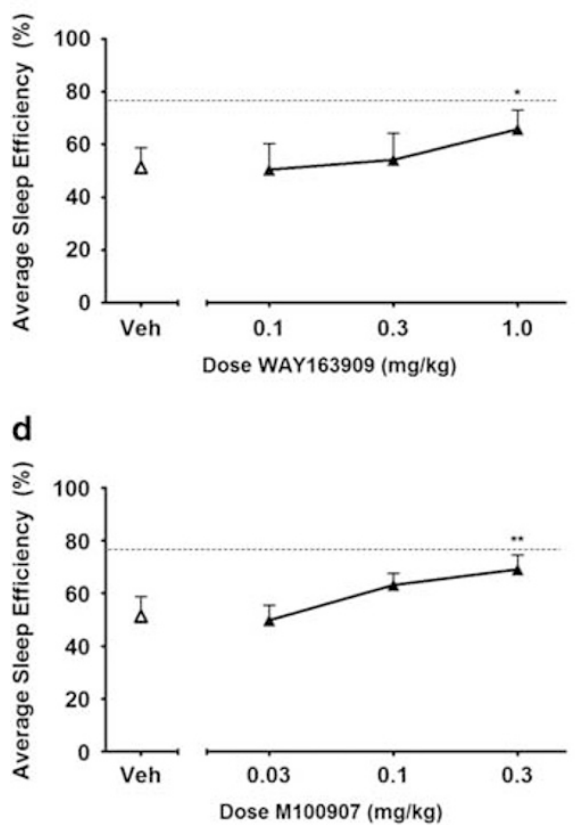

b

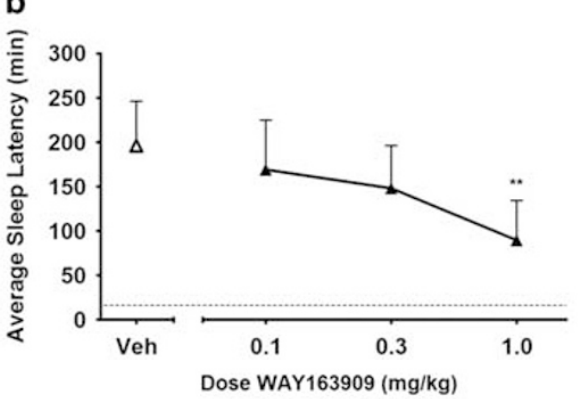

e

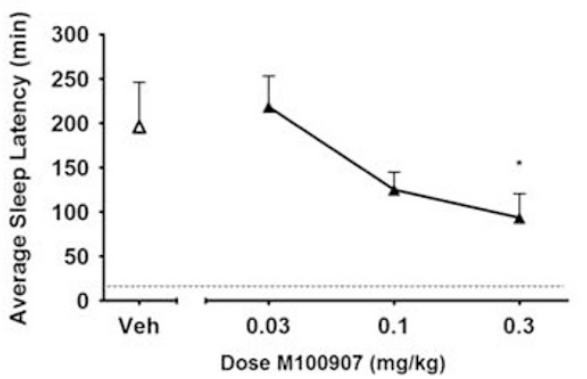

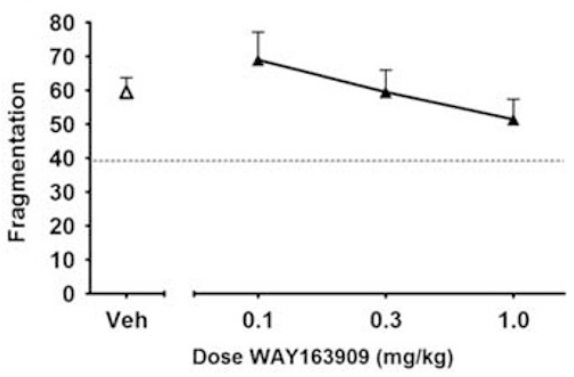

f

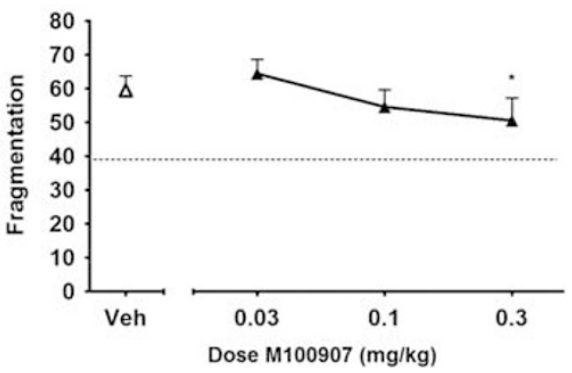

Figure 2 5- $\mathrm{HT}_{2}$ receptor agonist, 5- $\mathrm{HT}_{2 \mathrm{~A}}$ receptor antagonist, and METH SA effects on actigraphy-based sleep measures. Dose-effect curves ( $\left.\mathrm{N}=4\right)$ for the effects of WAY and MIOO on nighttime activity during METH SA. The highest dose of WAY significantly improved actigraphy-based measures of sleep efficiency $(F(3,3)=4.90, p=0.0142)$ and latency $(F(3,3)=6.04, p=0.0067)$ that had been disrupted by METH SA compared with vehicle, but had no effect on fragmentation ( $F(3,3)=3.90, p=0.0297$ ). (a) Sleep efficiency (\%), (b) sleep latency (minutes), and (c) fragmentation (unitless index). The highest dose of MI 00 significantly improved actigraphy-based sleep efficiency $(F(3,3)=9.24, p=0.0041$ ), latency $(F(3,3)=7.288, p=0.0088)$, and fragmentation $(F(3,3)=7.22$, $p=0.009 \mathrm{I}$ ) that had been disrupted by METH SA compared with vehicle. The lower doses of WAY and MI00 had no effect. (d) Sleep efficiency (\%), (e) sleep latency (minutes), and ( $f$ fragmentation (unitless index). All data were averaged over 5 days. Dotted lines indicate baseline levels of each measure in the absence of METH SA. Means \pm SE shown. METH SA, methamphetamine self-administration. $*_{p}<0.05, * * p<0.01$.
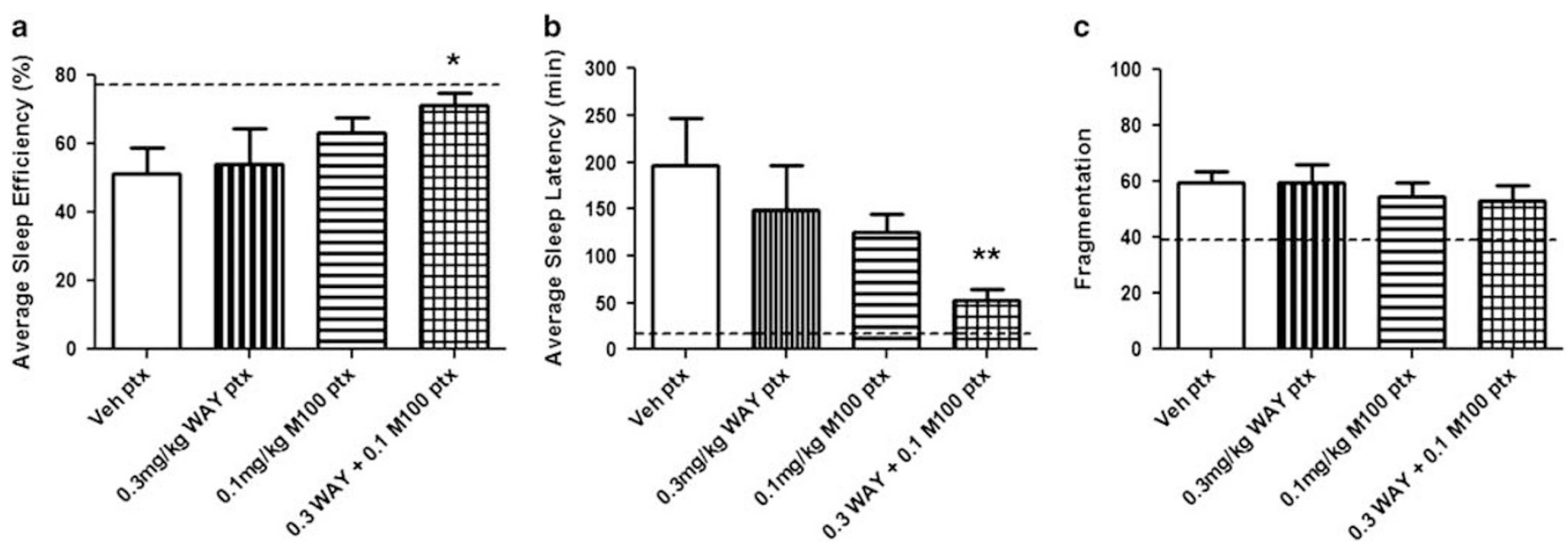

Figure 3 Co-administration of a 5- $\mathrm{HT}_{2 \mathrm{C}}$ receptor agonist and 5- $\mathrm{HT}_{2 \mathrm{~A}}$ receptor antagonist effects on METH-induced disruption of actigraphy-based sleep measures. Subjects $(\mathrm{N}=4)$ received nighttime pre-treatments of a combination of the highest ineffective dose of WAY $(0.3 \mathrm{mg} / \mathrm{kg})$ and $\mathrm{MIO0}(0.1 \mathrm{mg} / \mathrm{kg})$ during METH SA. Each ineffective dose alone had no effect on actigraphy-based sleep parameters compared with vehicle, but the combination dose significantly improved actigraphy-based measures of sleep efficiency $(F(3,3)=5.74, p=0.0178)$ and latency $(F(3,3)=6.06, p=0.0152)$ that had been disrupted by METH SA. Fragmentation ( $F(3,3)=3.247, p=0.0742$ ) was not affected. (a) Sleep efficiency (\%), (b) sleep latency (minutes), and (c) fragmentation (unitless index). All data were averaged over 5 days. Dotted lines indicate baseline levels of each measure in the absence of METH SA. Means \pm SE shown. METH SA, methamphetamine self-administration. $* p<0.05, * * p<0.0$ I.

$+0.1 \mathrm{mg} / \mathrm{kg}$ M100) significantly increased sleep efficiency (Figure 3a) by approximately $20 \%(\mathrm{~F}(3,3)=5.74, p=0.0178)$ and decreased sleep latency (Figure $3 \mathrm{~b}$ ) from over $3 \mathrm{~h}$ to less than an hour compared with vehicle $(\mathrm{F}(3,3)=6.06$, $p=0.0152$ ). For sleep fragmentation (Figure $3 \mathrm{c}$ ), there was no significant difference in the means across treatments (F $(3,3)=3.247, p=0.0742)$.

\section{Experiment 2}

5-HT ${ }_{2 C} R$ agonist and $5-H T_{2 A} R$ antagonist on baseline actigraphy-based sleep measures. Nighttime pretreatments of the highest dose of WAY $(1.0 \mathrm{mg} / \mathrm{kg})$ and M100 $(0.3 \mathrm{mg} / \mathrm{kg})$ were tested to determine if they had any effects on actigraphy-based measures of sleep in the absence 
of METH SA. Baseline measures were not significantly affected by the highest dose of WAY or M100 ( $p>0.05)$. Baseline sleep efficiency, sleep latency and fragmentation remained stable at $\sim 70 \%, \sim 30$ min and 50 units, respectively (data not shown).

\section{Experiment 3}

5-HT $T_{2 C} R$ agonist and $5-H T_{2 A} R$ antagonist on baseline daytime activity. Daytime pre-treatments with WAY and M100 in the absence of METH SA were tested in order to determine if they had any effects on actigraphy-based measures of general motor activity. The highest dose of WAY $(1.0 \mathrm{mg} / \mathrm{kg})$ significantly decreased total daytime activity $(\mathrm{F}(3,4)=6.56, p=0.0121)$ by approximately $27 \%$ compared with vehicle (Figure 4a). Total daytime activity (Figure 4b) was not significantly affected by any dose of M100 $(\mathrm{F}(3,3)=1.17, p=0.3752)$ and remained stable across treatments at $\sim 150000$ counts.

\section{DISCUSSION}

METH use has been widely associated with sleep disruption. We examined the effectiveness of a $5-\mathrm{HT}_{2 \mathrm{C}} \mathrm{R}$ agonist and a $5-\mathrm{HT}_{2 \mathrm{~A}} \mathrm{R}$ antagonist to normalize actigraphy-based sleep measures disrupted by METH SA. Further, we evaluated whether co-administration of these drugs would enhance their effectiveness. METH SA significantly disrupted activitybased parameters of sleep, reflected by longer sleep latencies, reduced sleep efficiencies and greater fragmentation. WAY and M100 improved actigraphy-based sleep measures disrupted by METH SA by increasing sleep efficiency and decreasing sleep latency. Moreover, co-administration of subthreshold doses of these drugs attenuated METH-induced disruption of sleep. Interestingly, METH intake was not affected by any nighttime pre-treatments.

METH has been self-administered by a variety of model organisms including rats (Roth and Carroll, 2004; Yokel and Pickens, 1973), cats (Balster et al, 1976), and NHPs (Balster and Schuster, 1973; Woolverton et al, 1984). In Experiment 1, rhesus monkeys reliably self-administered METH for 10 weeks during which their nighttime activity patterns were significantly disturbed, validating results from our previous study (Andersen et al, 2013). These data also support another study demonstrating that psychostimulants increase arousal and disrupt sleep parameters in NHPs (Murnane et al, 2013b).

To determine the roles of the $5-\mathrm{HT}_{2 \mathrm{C}} \mathrm{R}$ and $5-\mathrm{HT}_{2 \mathrm{~A}} \mathrm{R}$ in attenuating the effects of METH SA on nighttime activity, we evaluated a series of doses of WAY and M00. Both drugs improved activity-based sleep measures disrupted by METH SA, except for sleep fragmentation, which was not affected by WAY. Drug effects were observed on the first day of administration and there was no evidence for a change in effectiveness over the five consecutive days of treatment. The mechanisms by which WAY and M100 might exert these effects may be, in part, related to their effectiveness to modulate dopaminergic signaling. Specifically, these drugs attenuate psychostimulant-induced DA overflow in the striatum (Manvich et al, 2012; Murnane et al, 2013a). The highest dose of M100 was the only dose that significantly normalized nighttime activity and attenuated DA overflow in the caudate nucleus in a previous study (Murnane et al, $2013 \mathrm{~b}$ ). This evidence suggests that $0.3 \mathrm{mg} / \mathrm{kg}$ is a behaviorally relevant dose of $\mathrm{M} 100$, especially with respect to behaviors modulated by DA neurotransmission. However, it is important to note that these drugs were administered approximately $6-8 \mathrm{~h}$ after METH SA and so their acute effects to blunt psychostimulant-induced DA overflow cannot account for the attenuation of sleep disruption reported here. Importantly, the results support a role for both the $5-\mathrm{HT}_{2 \mathrm{C}} \mathrm{R}$ and $5-\mathrm{HT}_{2 \mathrm{~A}} \mathrm{R}$ in regulating the sleepdisrupting effects of METH and suggest that WAY and M100 may be of use in treating the sleep-disrupting effects of METH use.

We also determined the roles of the $5-\mathrm{HT}_{2 \mathrm{C}} \mathrm{R}$ and $5-\mathrm{HT}_{2 \mathrm{~A}} \mathrm{R}$ in regulating nighttime activity in the absence of METH SA. WAY and M100 had no effect on baseline nighttime activity. At baseline, sleep latencies were very short, fragmentation was low, and sleep efficiencies were over $80 \%$. It is difficult to improve upon these already near-optimal measures, so the lack of effect on baseline nighttime activity is likely due to a ceiling effect.

Full dose-effect curves for WAY and M100 on baseline daytime activity were conducted in order to determine whether they exhibited general motor-decreasing effects at any dose. WAY at the highest does, but not M100, did significantly decrease baseline daytime activity, indicating
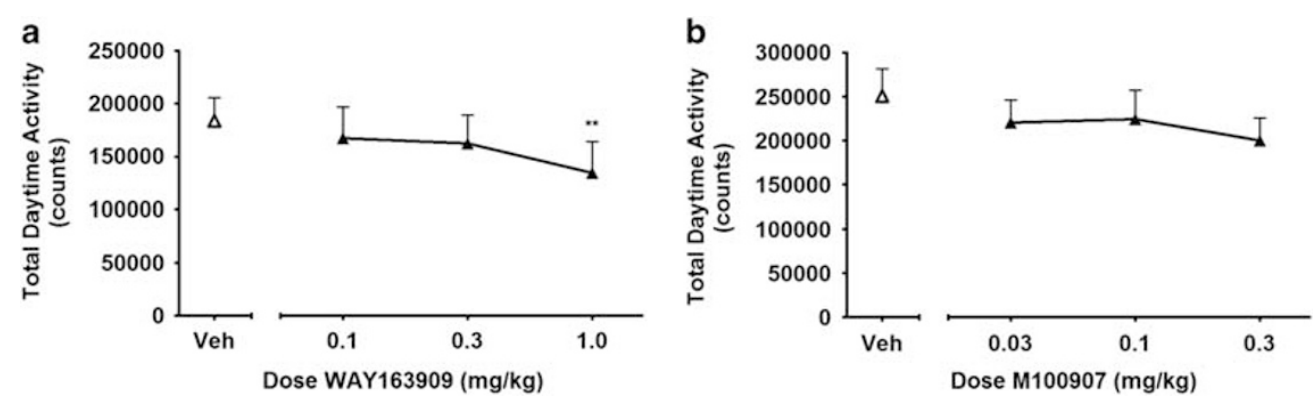

Figure 4 5- $\mathrm{HT}_{2 \mathrm{C}}$ receptor agonist effects on baseline daytime activity. The effects of WAY and MIO0 on baseline (no METH SA) daytime activity were determined $(N=5)$. (a) Dose-effect curve for the effects of WAY on baseline daytime activity and (b) dose-effect curve for the effects of MI00 on baseline daytime activity. Daytime pre-treatments with the highest dose of WAY significantly decreased total daytime activity compared with vehicle $(F(3,4)=6.56$, $p=0.0121)$. The lower doses of WAY and all the doses of MIOO $(F(3,3)=1.17, p=0.3752)$ had no effect on this parameter. Means \pm SE shown. METH SA, methamphetamine self-administration. $*$ * $p<0.01$. 
that it has general motor-suppressing effects. Incidentally, this was also the only dose that significantly improved activity-based parameters of sleep disrupted by METH SA. This agrees with previous work in rodents suggesting that M100 has no effect on baseline motor activity (Fletcher et al 2002). Therefore, general motor-suppressing effects may have confounded the effect of WAY, but not M100, on nighttime activity.

To demonstrate that agonism at the $5-\mathrm{HT}_{2 \mathrm{C}} \mathrm{R}$ and antagonism at the $5-\mathrm{HT}_{2 \mathrm{~A}} \mathrm{R}$ can be combined to enhance the individual effects of each, we chose the highest ineffective doses of WAY $(0.3 \mathrm{mg} / \mathrm{kg})$ and $\mathrm{M} 100(0.1 \mathrm{mg} / \mathrm{kg})$ at attenuating the effects of METH SA on nighttime activity when administered alone. These doses when given in combination significantly improved activity-based sleep efficiency and latency, but not fragmentation, that had been disrupted by METH SA, an interaction consistent with another study showing that combined administration of WAY and M100 can enhance their individual effects on several liability factors for relapse to cocaine (Cunningham et al, 2013). As before, drug effects were observed on the first day of treatment and there was no change in effectiveness over time. By combining subthreshold doses of WAY and M100, these drugs achieved the same level of effectiveness at attenuating the effects of METH SA on nighttime activity as either high dose alone.

The mechanism by which these enhanced effects are being mediated likely involves the effectiveness of each drug at attenuating psychostimulant-induced DA overflow in the striatum. 5- $\mathrm{HT}_{2 \mathrm{C}}$ agonists (Manvich et al, 2012) are effective in reducing DA overflow in the nucleus accumbens. Conversely, M100 is effective in reducing DA overflow in the caudate nucleus/dorsal striatum (Murnane et al, 2013b). Dual attenuation of DA overflow in the caudate nucleus and the nucleus accumbens may account for the enhanced effect of the combination treatment. These results suggest that pharmacological agents targeting the 5- $\mathrm{HT}_{2 \mathrm{C}} \mathrm{R}$ and the 5$\mathrm{HT}_{2 \mathrm{~A}} \mathrm{R}$ may be of use in treating the sleep-disrupting effects of METH abuse.

While we found that WAY and M100, both alone and in combination, significantly improve sleep efficiency and reduce sleep latency, we did not detect a significant effect of WAY or the combination on fragmentation. Of the three measures, fragmentation exhibits the highest variation in the same individual across nights, which may explain why it remained unaffected by some of the pharmacological manipulations. For sleep to be improved, all three variables do not need to be altered. An increase in sleep efficiency or decrease in latency or fragmentation alone represents an improvement in sleep and there is no clear consensus regarding whether any of these dependent measures are more important for improving sleep than the others.

There is now a growing body of evidence supporting a significant comorbidity between stimulant abuse and sleep disorders, which have a myriad of adverse health outcomes. Owing to the negative, and often unpleasant consequences of sleep deprivation, stimulant users may be motivated to continue or escalate use throughout the night or over several days of binge drug-taking in order to avoid these. In addition, impaired judgment due to sleep disruption could contribute to risky behavior and poor decision-making that perpetuates ongoing drug use. We hypothesized that pharmacological interventions capable of rescuing sleep disrupted by ongoing stimulant use may limit binge drugtaking and perhaps skew decision-making toward secession of use. However, our results suggest that rescuing sleep that has been disrupted by ongoing METH use does not lead to reduced drug-taking the following day, even after repeated dosing. Regardless, these sleep-improving interventions could negate some of the negative health outcomes caused not directly by stimulant use but by the sleep disruption that ensues. To the best of our knowledge, this is the first study to evaluate the efficacy of any pharmacological intervention in reducing the effects of stimulants on nighttime activity in NHPs.

In summary, this study is the first to provide evidence that 5- $\mathrm{HT}_{2 \mathrm{C}} \mathrm{R}$ and $5-\mathrm{HT}_{2 \mathrm{~A}} \mathrm{R}$ mediate the sleep-disrupting effects of METH. Agonism of the $5-\mathrm{HT}_{2 \mathrm{C}} \mathrm{R}$ and antagonism of the $5-\mathrm{HT}_{2 \mathrm{~A}} \mathrm{R}$ improved METH-induced disruption of sleep efficiency and latency, both alone and in combination, indicating that serotonergic signaling mediated through these receptors has a profound impact on sleep quality in NHPs during METH SA. Additional clinical studies are needed to evaluate whether the efficacy of these drugs can be extended to humans, while more preclinical studies are needed to determine drug safety when used alone and in combination. These results will have important implications because METH use continues to increase in several countries including the USA. Pharmacological tools that attenuate the impact of METH and other psychostimulants on sleep should be considered as potential strategies to treat the sleeprelated effects of stimulant use.

\section{FUNDING AND DISCLOSURE}

This research was supported by USPHS Grants DA10344 (to LLH), DA31246 (to LLH), and P51OD11132 (Yerkes National Primate Research Center) and by AFIP and CNPq (to MLA). The authors declare no conflict of interest.

\section{ACKNOWLEDGMENTS}

We express our gratitude to Laís Berro, Lisa Neidert, and Juliet Brown for their excellent assistance with the experiments.

\section{REFERENCES}

Adrien J (2004). Implication of serotonin in the control of vigilance states as revealed by knockout-mouse studies. J Soc Biol 198: 30-36.

Andersen ML, Kessler E, Murnane KS, McClung JC, Tufik S, Howell LL. (2010). Dopamine transporter-related effects of modafinil in rhesus monkeys. Psychopharmacology 210: 439-448.

Andersen ML, Perez Diaz M, Murnane KS, Howell LL. (2013). Effects of methamphetamine self-administration of actigraphybased sleep parameters in rhesus monkeys. Psychopharmacology 227: 101-107.

Andersen ML, Sawyer EK, Howell LL (2012). Influence of chronic RTI-336 treatment on behavior and hormonal levels in rhesus monkeys. Exp Clin Psychopharmacol 20: 77-83.

Appelhans BM, Janssen I, Cursio JF, Matthews KA, Hall M, Gold EB et al (2013). Sleep duration and weight change in midlife women: The SWAN Sleep Study. Obesity 21: 77-84. 
Balster RL, Kilbey MM, Ellinwood EH (1976). Methamphetamine self-administration in the cat. Psychopharmacologia 46: 229-233.

Balster RL, Schuster CR (1973). A comparison of d-amphetamine, L-amphetamine, and methamphetamine self-administration in rhesus monkeys. Pharm Biochem Behav 1: 67-71.

Baron KG, Reid KJ, Malkani RG, Kang J, Zee PC (2016). Sleep variability among older adults with insomnia: associations with sleep quality and cardiometabolic disease risk. Behav Sleep Med 14: 1-14.

Bromidge SM, Dabbs S, Davies DT, Davies S, Duckworth DM, Forbes IT et al (2000). Biarylcarbamoylindolines are novel and selective 5-HT(2C) receptor inverse agonists: identification of 5-methyl-1-[[2-[(2-methyl-3-pyridyl)oxy]-5-pyridyl]carbamoyl]6-trifluoromethylindoline (SB-243213) as a potential antidepressant/anxiolytic agent. J Med Chem 43: 1123-1134.

Bryan CJ, Gonzales J, Rudd MD, Bryan AO, Clemans TA, Ray-Sannerud B et al (2015). Depression mediates the relation of insomnia severity with suicide risk in three clinical samples of U.S. military personnel. Depress Anxiety 32: 647-655.

Buxton OM, Marcelli E (2010). Short and long sleep are positively associated with obesity, diabetes, hypertension, and cardiovascular disease among adults in the United States. Soc Sci Med 71: 1027-1036.

Castro-Diehl C, Diez Roux AV, Redline S, Seeman T, Shrager SE, Shea S. (2015). Association of sleep duration and quality with alterations in the hypothalamic-pituitary adrenocortical axis: The multi-ethnic study of atherosclerosis (MESA). J Clin Endocrinol Metab 100: 3149-3158.

Cruickshank CC, Dyer KR (2009). A review of the clinical pharmacology of methamphetamine. Addiction 104: 1085-1099.

Cunningham KA, Anastasio NC, Fox RG, Stutz SJ, Bubar MJ, Swinford SE et al (2013). Synergism between a serotonin 5-HT2A receptor (5-HT2AR) antagonist and 5-HT2CR agonist suggests newpharmacotherapeutics for cocaine addiction. ACS Chem Neurosci 4: 110-121.

Dunlop J, Sabb AL, Mazandarani H, Zhang J, Kalgaonker S, Shukhina $\mathrm{E}$ et al (2005). WAY-163909 [(7bR, 10aR)-1,2,3,4,8,9,10,10aoctahydro-7bH-cyclopenta-[b][1,4]diazepino[6,7,1hi]indole], a novel 5-hydroxytryptamine 2C receptor-selective agonist with anorectic activity. J Pharmacol Exp Ther 313: 862-869.

Fletcher PJ, Phil D, Grottick AJ, Higgins GA (2002). Differential effects of the 5-HT2A receptor antagonist M100,907 and the 5-HT2C receptor antagonist SB242,084 on cocaine-induced locomotor activity, cocaine self-administration and cocaineinduced reinstatement of responding. Neuropsychopharmacology 27: $576-586$.

Frank MG, Stryker MP, Tecott LH (2002). Sleep and sleep homeostasis in mice lacking the 5-HT2c receptor. Neuropsychopharmacology 27: 869-873.

Freeman KB, Wang Z, Woolverton WL (2010). Self-administration of (+)-methamphetamine and (+)-pseudoephedrine, alone and combined, by rhesus monkeys. Pharmacol Biochem Behav 95: 198-202.

Gardner EL (2000). What we have learned about addiction from animal models of drug self-administration. Am J Drug SelfAdministr 9: 285-313.

Grandner MA, Jackson NJ, Pak VM, Gehrman PR. (2012). Sleep disturbance is associated with cardiovascular and metabolic disorders. J Sleep Res 21: 427-433.

Hasler BP, Smith LJ, Cousins JC, Bootzin RR. (2012). Circadian rhythms, sleep, and substance abuse. Sleep Med Rev 16: 67-81.

Howell LL, Wilcox KM (2001). Intravenous drug self-administration in nonhuman primates. In: Buccafusco JJ (ed). Methods of Behavior Analysis in Neuroscience. CRC: Boca Raton, pp 91-110.
Johanson CE, Schuster CR (1981). Animal models of drug self-administration. Adv Subst Abuse 2: 219-297.

Knight AR, Misra A, Quirk K, Benwell K, Revell D, Kennett G, Bickerdike M (2004). Pharmacological characterisation of the agonist radioligand binding site of 5- $\mathrm{HT}(2 \mathrm{~A}), 5-\mathrm{HT}(2 \mathrm{~B})$ and 5-HT(2C) receptors. Naunyn Schmiedebergs Arch Pharmacol 370: 114-123.

Mann TM, Williams KE, Pearce PC, Scott EA. (2005). A novel method for activity monitoring in small non-human primates. Lab Anim 39: 69-77.

Manvich DF, Kimmel HL, Howell LL (2012). Effects of serotonin 2C receptor agonists on the behavioral and neurochemical effects of cocaine in squirrel monkeys. J Pharmacol Exp Ther 341: 424-434.

Marshall BD, Grafstein E, Buxton JA, Qi J, Wood E, Shoveller JA et al (2012). Frequent methamphetamine injection predicts emergency department utilization among street-involved youth. Public Heath 126: 47-53.

Monti JM (2011). Serotonin control of sleep-wake behavior. Sleep Med Rev 15: 269-281.

Murnane KS, Andersen ML, Rice KC, Howell LL. (2013b). Selective serotonin $2 \mathrm{~A}$ receptor antagonism attenuates the effects of amphetamine on arousal and dopamine overflow in nonhuman primates. J Sleep Res 22: 581-588.

Murnane KS, Winschel J, Schmidt KT, Stewart LM, Rose SJ, Cheng $\mathrm{K}$ et al (2013a). Serotonin 2A receptors differentially contribute to abuse-related effects of cocaine and cocaine-induced nigrostriatal and mesolimbic dopamine overflow in nonhuman primates. J Neurosci 33: 13367-1374.

Perez AY, Kirkpatrick MG, Gunderson EW, Marrone G, Silver R, Foltin RW et al (2008). Residual effects of intranasal methamphetamine on sleep, mood, and performance. Drug Alcohol Depend 94: 258-262.

Qureshi SS, Basit-Ansari S, Qureshi MA, Zohra RR. (2014). The relationship between sleep and cognitive functioning in adult people. Pak J Pharm Sci 27: 2153-2156.

Roth ME, Carroll ME (2004). Sex differences in the acquisition of IV methamphetamine self-administration and subsequent maintenance under a progressive ratio schedule in rats. Psychopharmacology (Berl) 172: 443-449.

Smagula SF, Stone KL, Redline S, Ancoli-Islrael S, Barrett-Connor E, Lane NE et al (2016). Actigraphy- and polysomnographymeasured sleep disturbances, inflammation, and mortality among older men. Psychosom Med 78: 686-696 UC San Diego: 1588871. Retrieved from http://escholarship.org/uc/item/6sv2v9v7.

Terrill PI, Mason DG, Wilson SJ (2010). Development of a continuous multisite accelerometry system for studying movements duringsleep. Conf Proc IEEE Eng Med Biol Soc 2010: 6150-6153.

Troxel WM, Buysse DJ, Matthews KA, Kip KE, Strollo PJ, Hall M et al (2010). Sleep symptoms predict the development of the metabolic syndrome. Sleep 33: 1633-1640.

Tufik S, Andersen ML, Bittencourt LRA, Mello MT. (2009). Paradoxical sleep deprivation: neurochemical, hormonal and behavioral alterations. Evidence from 30 years of research. An Acad Bras Ciênc 81: 521-538.

Woolverton WL, Cervo L, Johanson CE (1984). Effects of repeated methamphetamine administration on methamphetamine selfadministration in rhesus monkeys. Pharmacol Biochem Behav 21: 737-741.

Yokel RA, Pickens R (1973). Self-administration of optical isomers of amphetamine and methylamphetamine by rats. J Pharmacol Exp Ther 187: 27-33.

Zhai L, Zhang H, Zhang D (2015). Sleep duration and depression among adults: a meta-analysis of prospective studies. Depress Anxiety 0: 1-7. 